\title{
TECHNICAL COLLEGES, UNIVERSITIES AND MEDICAL RESEARCH
}

\author{
Peter Baillie
}

There are no South Asian universities in the top 100 in the world as assessed by the stringent objective Peking criteria. ${ }^{1}$ There are many reasons for this but the most important understands what a university does as opposed to a technical college, which is unclear to many senior academicians but is easily correctable and has a profound influence on the type and quality of research carried out by universities.

Once a university concentrates on a curriculum, lectures and examines the students on the curriculum, it is simply informing them, which is what a technical college does. Technical colleges provide certificates (e.g. motor mechanics) to practice and specify a minimum standard based on the guidelines of the course. They teach what and how and "research" is actually audit which only applies to the institution in which it is carried out. Most devastatingly having guidelines as the standard stops any original thought development of a really expert mind ${ }^{2}$ capable of sustaining and advancing medicine in Pakistan where overseas guidelines are often followed. Certification, of course, does have a place but is the PMDC and CPSP as these bodies set minimum standards for practice. It is the role of universities to produce excellence. It is clear from the above discussion the most universities are technical colleges in many countries such as Pakistan in these days of communication and globalization where administration, organization and discipline are viewed as an end, rather than the means to an end. What then, is a university and how does it affect the type and quality of research? Firstly, a university does not simply inform students, it teaches them how to think by asking the question why about everything. This does not close knowledge as with a technical college, although uncertainty is inherent ${ }^{3}$ in such people with the priceless attribute of the prepared mind. As Louise Pasteur pointed out - chance (in practice and research) occurs far more commonly to the prepared mind. Consequently, a university and its occupants are a state of mind, endlessly questioning even entrenched attitudes. As the individual level every patient encounter is directed by why has this patient the disease and not other family members and secondly individualization - should I treat this patient differently from the dictates of guidelines? This state of mind clearly engenders much more research. The nature of university research is therefore clearly different to the audit of technical college by initially asking why and can be on a large or small scale. The problem is that it requires an up to date knowledge of basic science which is doubling every 18 months and simply to keep up requires reading 33 clinical articles daily ${ }^{4}$ which has only been achieved at only one medical university in Pakistan to my knowledge. Furthermore, as the emphasis of modern universities is away from the simple. Flexnerian concept of single patient treatment of a disease focuses towards prevention, utilizing genomics $^{5}$ and systems biology. This requires universities to move beyond simply being service ${ }^{6}$ - an institution dependent on the perceptions of sick patients about when to seek instant cure at hospital. A modern university is dependent on a large community where problem can be defined and solved in addition to Flexnerian treatment. A third type of research is international collaborative research. This can be very expensive, and has two arms:

(1) Pharmaceutical company out sourcing is subject to bias and more recently ethical considerations in developing countries.

(2) International donor organizations such as WHO, UNICEF, DFID and THE BILL and MELINDA GATES FOUNDATION. These are fundamentally acceptable and usually have linkages with developed world universities. They do tend to be based on developed world approaches ${ }^{7}$ to a country such as Pakistan. A strong university input is required to produce more relevant applications rather than HEC or governmental control of such studies. A thesis developed as a result of such studies requires the question why to generate an hypothesis, calculate the numbers needed to obtain a generalizeable conclusion (based on an up to date review of the subject as a synopsis - apart from the seminal reference in a thesis, anything older than three years is simply outdated) as well as the discipline needed to complete the study in an adequate time period. Above all, it requires a major addition to knowledge making the student a world authority, not simply describing a technical niche' - a major problem in biological sciences and medicine.

In no way this research comparable to audit where 100 cases or 1000 cases or one years experience are analyzed - even with controls. These audit type findings are simply not applicable to anything other than the technical college carrying them out. It is assumed that research entails much funding and expensive technical input. This is not necessarily true. The types of research that can be carried out at a university are as follows:

Proof of principle. These are often pilot studies and require very few study subjects and can even be con- 
cepts. A157 article in Nature, ${ }^{7}$ the top scientific journal, contained no experimental work but resulted in 2 Cambridge PhD's and Nobel prizes for Watson and Crick. As a byline, it would probably not be accepted by many modern editors nor would the original penicillin publication such is the present day dominance of good statistics over bad Biology. Translational research. This is perhaps the major reason for western involvement in developing countries such as Pakistan. ${ }^{8}$ A basic science advance is applied clinically without the intermediate steps being clarified. It is not expensive. These approaches are what real universities should be doing in research. There are many difficulties interfering with this process in Pakistan. Seventy five percent of total health spending in Pakistan is in the private sector which is entrepreneurial in nature and anti academic with many senior professors having very divided loyalties. The government approach to universities is also incorrect. It is no accident that 18 of the top 20 universities in the world are in the United States. The public universities are funded by the governments who have no part in how they function. The University of Wisconsin (no. 16 in the world) illustrates how a university functions and its role in Society. After 3 years of bad crops in this largely farming state, the university was approached and 3 professors investigated the problem. A practical solution was submitted to the government and the problem solved within 6 months. In Pakistan, the government would institute a committee and arrive at another belated unsuccessful 5 years government plan after prolonged bureaucratic deliberations, largely bypassing universities. Medicine is a particularly difficult field because of its broad application and doctors in Pakistan have to be better than their colleagues in other countries because of a double disease load and fewer facilities. The expensive, litigious, technical economically driven America approach (which is on $37^{\text {th }}$ in the world in outcome measures) ${ }^{9}$ is as inapplicable to Pakistan as is the European model where medicine has been relegated to the status of a job rather than a profession and simply another social service. ${ }^{10} \mathrm{~A}$ better status should be provided for Pakistani doctors incorporating the best of other approaches but with the realization of our unique status and that the objective of the millennium ${ }^{11}$ generation is the production of a capable doctor (rather than simply a competent one) with the key ability of being able to unlearn what has been learned before and relearn. ${ }^{12}$ This is the role of a true university and not a technical colleges or certifying bodies, but requires a hugely increased academic input and standard. "The plans for the future are made by the leaders of today based on the experience of yesterday - and are bound to fail".

\section{REFERENCES}

1. Enserink M. University Ranking; Who Ranks The University Rankers? Science. 2007;317:1026-8.

2. Ross PE. The Expert Mind. Scientific Am. 2006; 297(8): 46.

3. Greene GF and Tsouroufli $M$. The nature of medical evidence and its In gerent uncertainty for clinical consultations; qualitative study. $\mathrm{Br}$ Med $\mathrm{J}$. 2005; 330: 511-3.

4. Sackett DL. Clinical epidemiology. What, who and whither? J Clin Epidemiol. 2002; 55: 1161-66.

5. Ansell SM, Ackerman MJ, Black JL, Roberts LR, Tefferi A. Primer on medical genomics. Part VI: Genomics and molecular genetics in clinical practice. Mayo Clin Proc. 2003;78(3):307-17.

6. Morel NM, Holland JM, van der Greef J, Marple EW, Clish C, Loscalzo J, et al. Primer on medical genomics. Part XIV: Introduction to systems biology--a new approach to understanding disease and treatment. Mayo Clin Proc. 2004; 79(5):651-8.

7. Mark DB, vander Werf FJ Simes RJ, et al. Cardiovascular disease on a global scale: defining the path forward for research and practice. Eur Heart J. 2007; $78-84$.

8. Zerhoni EA. Translational and clinical sciences time for a new vision. New Eng J Med. 2005; 353: $1621-5$.

9. Schroeder SA. We can do better - improving the health of the American people. New Eng J Med. 2007: 357; 1221-8.

10. Williams $G$ and Lau A. Reform of undergraduate medical teaching in the United Kingdom, a triumph of evangelism over common sense. Br Med J. 2004; 329: 92-4.

11. Howell LP, Servis G, Bonham A. Multigenerational challenges in academic medicine: UC Davis's Responses. Acad Med. 2005; 80: 527-32.

12. Amdekar YK. Changing trends - a challenge to the "Already Trained". Ind Pediatr. 2005; 42: 215-20.

AUTHOR AFFILIATION:

Prof. Peter Baillie

Dean, Biological Sciences and

Head, Department of Nutrition

Baqai Medical University, Karachi-Pakistan.

Email: nutrition_bmu@hotmail.com 